\title{
Benign and Malignant Breast Disease in South Wales: A Study of Urinary Steroids
}

\author{
E. H. D. CAMERON, ${ }^{*}$ B.SC., PH.D. ; K. GRIFFITHS, † B.SC., PH.D. ; E. N. GLEAVE, $\ddagger$ M.B., F.R.C.S. \\ H. J. STEWART, $\$ M.B., F.R.C.S.ED. ; A. P. M. FORREST, M.D., CH.M., F.R.C.S.(ENG.,ED.,GLASG.) \\ H. CAMPBELL, $\mathbb{9}$ M.B., F.S.S.
}

British Medical fournal, 1970, 4, 768-771

\begin{abstract}
Cummary: The levels of aetiocholanolone, androsterone, and 17-hydroxycorticosteroids were measured in women without known disease of the breast, in women with benign breast disease, and in women with primary and advanced breast cancer. Statistical analysis showed there was no difference in the excretion of urinary 17 hydroxycorticosteroids in the various groups of patients. Detailed analysis of the aetiocholanolone and androsterone. levels, however, indicated.sthat patients with advanced localized disease excreted significantly less of these 11deoxy-17-oxosteroids than those in the other groups.
\end{abstract}

\section{Introduction}

The initial report (Bulbrook, Greenwood and Hayward, 1960) showing a statistical link between the urinary excretion of 17hydroxycorticosteroids (17-OHCS) and 11-deoxy-17ketosteroids (11-DOKS) and the :esponse of patients with breast cancer to endocrine ablation has been followed by several similar observations in other centres. The current position regarding steroid excretion in patients with breast cancer has been amply covered (Bulbrook, 1965; Hayward and Bulbrook, 1968; Bulbrook, 1969). In summary, the findings were that those women with advanced cancer of the breast who had a relatively high ratio of $11-\mathrm{DOKS}$ to $17-\mathrm{OHCS}$ in the urine (as expressed by the discriminant function 80-80 (17-OHCS in mg.) + aetiocholanolone. in $\mu \mathrm{g}$.) had a better response to endocrine ablation, particularly hypophysectomy.

The predictive value of this "discriminant function" is strengthened by inclusion of the free period and menopausal status (Atkins et al., 1964). The results from other centres have shown that the ability to "discriminate" between those who would respond and those who would not varies considerably, and unanimity in the field has yet to be achieved. The results of the Portsmouth group (Miller, Durant, Jacobs, and Allison, 1967; Miller and Durant, 1968), who have collaborated closely with Bulbrook and his colleagues on methodological problems (Thomas, Bulbrook, Durant, Miller, and Ross, 1969) agree closely. On the other hand, two other centres were unable to show satisfactory discrimination between the responders and non-responders (Ahlquist, Jackson, and Stewart, 1968; Wade, Davis, Tweedie, Clarke, and Haggart, 1969), and indeed Thomas, Bulbrook, and Hayward (1967) did not obtain quite such good discrimination in their second and somewhat larger series studied. Thus the value of these urinary steroid analyses has remained uncertain.

\footnotetext{
* Assistant Director, Tenovus Institute for Cancer Rescarch, Welsh National School of Medicine, Cardiff CF4 4XX

Director, Tenovus Institute for Cancer Research, Welsh National School of Medicine, Cardiff CF4 4XX.

$\ddagger$ Lecturer in Surgery, Welsh National School of Medicine, Roval Infirmary, Cardiff CF2 1SZ.

\& Honorary Assistant Lecturer in Surgers, Welsh National School of Medicine, Royal Infirmarv, Cardiff (SF is\%. Present apnointment: Medicine, Royal Infirmary, Cardiff CF2 1S\%. Present appointm

Senior Registrar in Radiotheranv, Royal Infirmary, Edinburgh 3.
Professor of Surgery, Welsh National School of Medicine, Royal Professor of Surgery, Welsh
Infirmary, Cardiff CF2 $1 \mathrm{SZ}$.

- Professor of Medical Statistics. Welsh National Schonl of Medicine,
} Royal Infirmary, Cardiff CI: $1 \mathrm{SZ}$.
Discrimination apart, Bulbrook, Hayward, and their colleagues (Hayward and Bulbrook, 1968) have also shown that about half the patients with primary breast cancer have abnormally low excretion of aetiocholanolone and that the survival rates, up to eight years after mastectomy, are greater in those patients with normal values. This was the first observation that abnormal values of urinary steroids may be present at the stage of primary disease and that they may have an influence on prognosis.

The present study was undertaken to examine the patterns of steroid excretion in women with benign and malignant diseases of the breast in South Wales.

\section{Patients and Methods}

Estimations of urinary steroids were made in a total of 177 women. Of these 21 were patients without known breast disease or malignant disease of any kind who had been admitted to hospital. for elective general surgical operations; 63 had benign disease of the breast, proved by excision biopsy of a palpable lump, 30 had primary breast cancer, subsequently treated by mastectomy, and 63 were patients with advanced breast cancer, subsequently treated by hormone administration or ablation of endocrine glands. Twenty-one patients in this advanced group had disease limited to the breasts, chest walls, regional lymph nodes or pleural cavity (localized disease), and 42 had osseous or visceral metastases (generalized disease) with or without localized disease.

Solvents and Reagents.-Ammonium sulphate, trimethylchlorosilane, hexamethyldisilazane, propane-1,2-diol, and sodium dithionite were of ordinary B.D.H. laboratory grade. All other chemicals were of analytical grade. Ethanol (A.R. grade) was obtained from Burroughs, London, and used without further purification. Ethyl acetate was purified by washing. three times with a one-tenth volume of distilled water, dried over anhydrous $\mathrm{K}_{2} \mathrm{CO}_{3}$, and distilled. Analytical grade diethyl ether was tested for impurities by shaking a 5ml. portion with $2 \mathrm{ml}$. of $2 \%, \mathrm{~K}_{2} \mathrm{CO}_{3}$. Only batches giving a completely colourless aqueous phase were used. Hexane and heptane were each purified by passage through a $1,300-\mathrm{cm}$. column $(3 \mathrm{~cm}$. internal diameter) of activated (grade 1) basic Woelm alumina (Camlab, Cambridge). Both solvents were then distilled.

$\beta$-Glucuronidase ( $2 \times 10^{\circ}$ units/g.) was purchased from Baylove Chemicals, Edinburgh.

Chromatography Apparatus and Reagents.-Paper chromatography was performed on strips of Whatman No. 4 chromatography paper (Reeves Angel, London) in the apparatus described by Thomas and Bulbrook (1964). Gas-liquid chromatography was carried out on a Pye (Cambridge) 104 Chromatograph (Model 24) with a flame ionization detector linked to a Leeds Northrup Speedomax W Recorder. Stationary phases XE60, SE30, and NPGS (neopentylglycol succinate) and GasChrom $Q$ support were obtained from Applied Science Laboratories, Philadelphia. 


\section{Procedure in Detail}

17-OHCS were measured according to the method of Few (1961). The technique used for the determination of the 11-DOKS and androsterone, aetiocholanolone, and dehydroepiandrosterone was essentially similar to that of Thomas and Bulbrook (1964) as modified by Thomas (1965). Since, however, various modifications in this method were introduced, the complete experimental approach used is now given for the sake of clarity.

Urine Collection.-Two consecutive 24-hour collections were made for each patient. Since the levels of urinary steroids vary considerably in response to stress, the conditions under which the collections were made were standardized as carefully as possible. All patients were in hospital (most were admitted to the same ward) and the collections made before treatment was carried out. The specimens were kept cool during collection and combined on completion of the 48-hour period. A portion was then stored in the frozen state without preservative until analysed.

Extraction.-Fifty millilitres of the combined specimen was brought to $\mathrm{pH} 6.5$, using $\mathrm{N} \mathrm{H}: \mathrm{SO}_{4}$ or $\mathrm{N} \mathrm{NaOH}$, and placed in a $250-\mathrm{ml}$. separating funnel. Accurately known quantities $(\sim 0.1$ $\mu \mathrm{Ci}$ ) each of [4- $\left.{ }^{11} \mathrm{C}\right] \mathrm{DHA}$ sulphate (DHAS) and $\left[7 \quad \alpha-{ }^{3} \mathrm{H} I \mathrm{DHA}\right.$ glucosiduronate (DHAG) (New England Nuclear Co., Boston) were added in a small volume of ethanol. Ammonium sulphate $(25 \mathrm{~g}$.) was then dissolved in the urine and the steroid conjugates were extracted with three $25-\mathrm{ml}$. portions of an ether : ethanol $(3: 1 \mathrm{v} / \mathrm{v})$ mixture. Extracts were combined and the droplets of aqueous layer allowed to settle. On removal of this material the organic phase was shaken with excess ether to precipitate dissolved ammonium sulphate. The mixture was finally filtered through Whatman No. 4 filter paper into a 250-ml. RB flask and taken almost to dryness in a rotary evaporator. The residue was dissolved in $10 \mathrm{ml}$. of ethanol, centrifuged and $8 \mathrm{ml}$. (equivalent to $40 \mathrm{ml}$. of urine) of the supernatant was dried in a stream of filtered air at $40^{\circ} \mathrm{C}$. in a B24 test-tube.

Hydrolysis and Solvolysis.- $\beta$-Glucuronidase powder, assayed by the method of Talalav, Fishman, and Huggins (1946), was homogenized in acetate buffer $(0.5 \mathrm{M}, \mathrm{pH} \mathrm{4.0)}$ and centrifuged to give a clear supernatant. This supernatant was diluted with acetate buffer to give a final concentration of about 2,000 units $/ \mathrm{ml}$. Then $5 \mathrm{ml}$. of this solution was added to the dry steroid extract and the mixture incubated for 16 hours at $40^{\circ} \mathrm{C}$. After the hydrolysis, $16.4 \mathrm{ml}$. of a $27 \%(\mathrm{w} / \mathrm{v}) \mathrm{NaCl}$ solution was added to the incubation mixture and the $\mathrm{pH}$ reduced to 1.0 with $4 \mathrm{~N}$ $\mathrm{H}_{2} \mathrm{SO}_{4}$. Extraction of free steroids and conjugates was effected by shaking twice with $20-\mathrm{ml}$. volumes of ethyl acetate. Pooled extracts were then incubated for four hours at $50^{\circ} \mathrm{C}$. (Burstein and Lieberman, 1958). On reduction of the volume to about $10 \mathrm{ml}$., 30 $\mathrm{ml}$. of $\mathrm{n}$-heptane was added and the mixture shaken successively three times with $5 \mathrm{ml}$. of $5 \%, \mathrm{Na}_{2} \mathrm{~S}_{2} \mathrm{O}_{i}$ in $\mathrm{N} \mathrm{NaOH}(\mathrm{w} / \mathrm{v})$ and twice with $2.5 \mathrm{ml}$. of distilled water. As also found by Thomas and Bulbrook (1964) this procedure effectively removed most of the urinary pigments, and on evaporating the solution to dryness the residue was transferred to a Bl4 test-tube with three more 4-ml. volumes of ethanol. Finally, this solution was taken to dryness and the residue concentrated in the bottom of the tube.

Paper Chromatography.-Strips of Whatman No. 4 chromatography paper were prepared according to the design of Thomas and Bulbrook (1964). The extract was applied to the origin and the bottom half of the chromatogram dipped in a $30 \% \mathrm{v} / \mathrm{v}$ solution of propane-1,2-diol in methanol. This solution was then allowed to "run up" to the origin by capillary action, and when the process was complete the chromatogram was removed, shaken, and allowed to dry for 10 minutes. Chromatography was then carried out exactly as described by the above authors and the heptane eluate (fraction, 0.05-3.5 ml.) evaporated to dryness in a B14 test-tube.

Radioactivity Measurement and Derivative Formation.-The dried residue was dissolved in $1 \mathrm{ml}$. of ethanol containing $10 \mu \mathrm{g}$. of $5 \alpha$-androstane- $3 \alpha, 17 \beta$-diol, and $0.1 \mathrm{ml}$. of this solution was removed and placed in a liquid scintillation phial. On evaporation of the solvent the residue in the phial was dissolved in $10 \mathrm{ml}$. of toluene containing $3 \mathrm{~g} . / 1$. PPO and $0.1 \mathrm{~g} . / 1$. dimethyl POPOP (Thorn Electronics, London) and the quantity of ${ }^{11} \mathrm{C}$ and ${ }^{3} \mathrm{H}$ determined by means of a Nuclear Chicago Liquid Scintillation Spectrometer Mk.I. The remainder of the ethanolic solution was meanwhile taken to dryness in a stream of $\mathrm{N}_{2}$, desiccated for 30 minutes, and redissolved in a mixture of $\mathrm{n}$-hexane (200 $\mu \mathrm{l}$.), hexamethyldisilazane $(250 \mu \mathrm{l}$.), and trimethylchlorosilane $(100 \mu \mathrm{l}$.). On standing overnight a portion of the solution was injected without further treatment on to the column of the gas chromatograph. This procedure was found to give quantitative trimethylsilyl ether formation.

Gas-Liquid Chromatography.-Initially of $275-\mathrm{cm}$. glass column (4 mm. internal diameter) was packed with GasChrom Q (100-120 mesh) supporting $0.35 \% \mathrm{SE}-30$ and $0.60 \% \mathrm{XE}-60$ prepared as a "hybrid" column by successively evaporating solutions of each phase down on to the support. This type of column, however, did not give adequate separation of androsterone and aetiocholanolone in our hands, and consequently the last $60 \mathrm{~cm}$. (detector end) was replaced by GasChrom Q supporting a $1 \%$ NPGS phase. The column was conditioned at $210^{\circ} \mathrm{C}$. for 48 hours and operated isothermally at $190^{\circ} \mathrm{C}$. with a $\mathrm{N}_{2}$ flow rate of $60 \mathrm{ml} . / \mathrm{min}$. This column was found to give excellent separations of all the steroids encountered, including the contaminant described by Thomas (1965), and was thence used throughout the study.

\section{Results}

Preliminary statistical analysis of the urinary steroid levels showed that the absolute values of each steroid were not normally distributed around the mean, but had a definitely skew distribution. A unimodal and symmetrical distribution was, however, obtained by conversion of the values to logarithms to the base 10 , and logarithmic values were therefore used in all subsequent analyses.

Comparison of the age distribution within each group (Table I) showed an obvious difference. The mean ages of the primary and advanced groups were similar. Those of the normal and benign groups, however, were lower, differing from the primary and advanced by seven and fifteen years, respectively.

\section{$\mathrm{C}_{19}$-steroid Analysis}

Comparison of the logarithmic values of aetiocholanolone showed that though there was no difference between the mean values of the normal, benign, and primary groups (Table II) there was a difference when the advanced group as a whole was compared with each of the other groups. This difference reached statistical significance in the case of the benign and primary groups $(P<0.01)$, and the fact that it did not reach significance when the advanced group was compared with the normal group $(P<0 \cdot 2)$ probably reflects the small size of the sample. Similarly, when the mean logarithmic values for androsterone in each group were compared there was no difference between the normal, benign, and

TABle I.-Number of Patients, Mean Ages, and Standard Deviations of Normal, Benign, Primary, and Advanced Groups

\begin{tabular}{|c|c|c|c|c|}
\hline \multicolumn{3}{|c|}{ Group } & No. of Patients & Mean Age Standard Deviation \\
\hline $\begin{array}{l}\text { Normal } \\
\text { Benign } \\
\text { Primary } \\
\text { Advanced }\end{array}$ & $\begin{array}{l}\cdots \\
\cdots \\
\cdots\end{array}$ & $\begin{array}{l}\cdots \\
\cdots \\
\therefore\end{array}$ & $\begin{array}{l}21 \\
63 \\
30 \\
63\end{array}$ & $\begin{array}{r:r}\mathbf{4 8} \cdot 6 & 15 \cdot 1 \\
38 \cdot 2 & 9 \cdot 4 \\
53 \cdot 6 & 10 \cdot 4 \\
53 \cdot 4 & 8 \cdot 7\end{array}$ \\
\hline $\begin{array}{l}\text { Local } \\
\text { General }\end{array}$ & $\ldots$ & 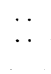 & $\begin{array}{l}21 \\
42\end{array}$ & $\begin{array}{c}53.4 \div 7.9 \\
53.3+9.3\end{array}$ \\
\hline
\end{tabular}

TABLE II.-Mean of Logarithmic Values of the 17-OHCS, Aetiocholanolone, and Androsterone with the Standard Deviation for the Normal, Benign, Primary, and Adranced Groups

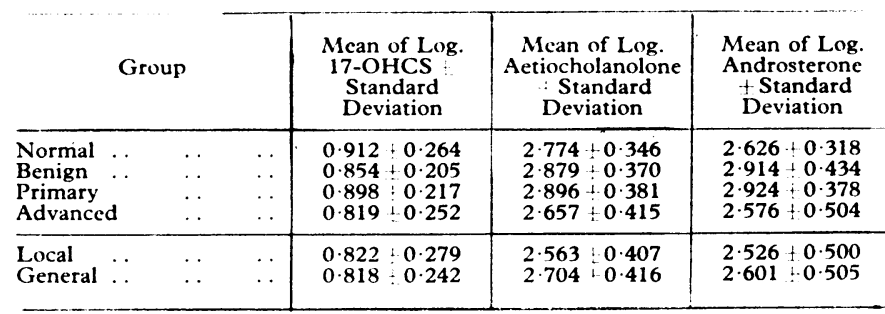


TABle III.--Analysis of Covariance, Patients Aged 38 Years and Over, $x=$ Age in Years. $y=\log 10$ (Aetiocholanolone in mg./24 hr.)

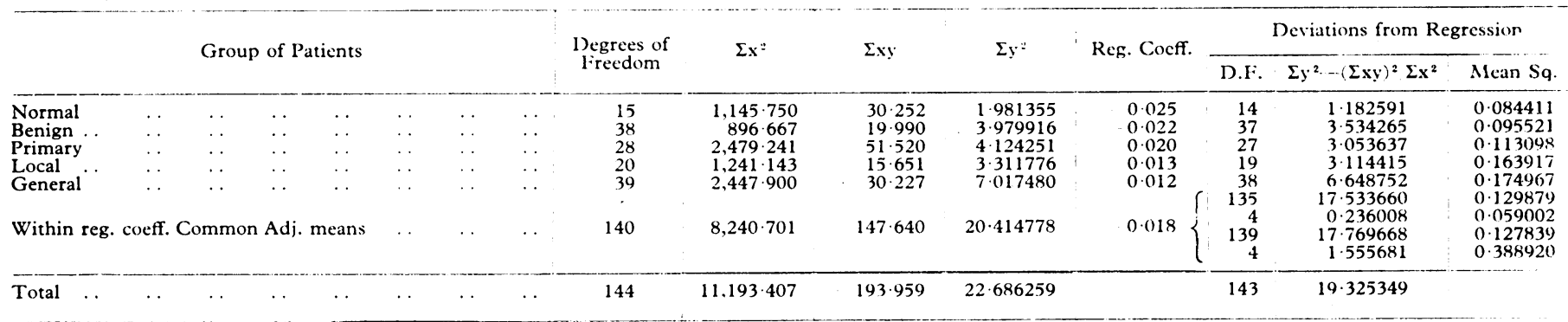

Slope: $F=0 \cdot 454$, D.F. 4,135. Not significant.

Elevation: $F=3.042$, D. F. 4,139. Significant at 0.05 level.

primary groups. A significant difference was, however, found when the advanced group was compared with the benign and primary groups $(P<0.01)$, though no difference was found between the advanced and normal groups $(P<0.5)$.

More detailed statistical analysis of the urinary $\mathrm{C}_{19}$-steroid excretion values were then undertaken. Since there was an age difference between the groups studied, the logarithmic values of aetiocholanolone were related to age for each patient. The values for normal patients and those with benign disease were found to increase during early adult life and then decrease with advancing age. The best calculated curve was a parabola which gave a maximum aetiocholanolone excretion between 38 and 40 years of age in each of the two groups (Fig. 1). Since there were few patients with breast cancer below the age of 38 , the further analysis was limited to patients over that age when a linear regression fitted the association between the logarithmic values of aetiocholanolone and age.

Analysis of covariance showed that the regression coefficients for the normal, benign, primary, and advanced groups were similar (Table III) and that a common regression coefficient could be used. Following from this, regression lines were drawn which showed that patients with advanced disease were different from the others and had significantly lower logarithmic levels of aetiocholanolone regardless of age (Fig. 2). To examine this difference further, the patients were considered according to the distribution of their disease, and regression lines were drawn separately for those with advanced local and those with advanced general disease (Fig. 3). They confirmed that the group with advanced localized disease was distinct from all others and that such patients have significantly lower levels of aetiocholanolone.

Calculations of the pooled standard deviation were determined for patients aged 50 and used to test the significance of difference between pairs of expected mean values. These studies confirmed that the group with advanced localized disease was distinct from all others and that such patients have significantly lower levels of aetiocholanolone when adjusted for age. When the difference in logarithmic values between the advanced localized disease and each of the other groups was converted back to a primary number, it was about $500 \mu \mathrm{g}$., or $45 \%$ of the mean value of each of the other groups.

The normal and primary groups behaved in a similar manner whereas the benign group had levels of aetiocholanolone little different from those of the patients in the advanced group. The differences between these four groups did not, however, reach statistical significance.

A similar analysis of the androsterone results was undertaken. There was a similar relationship between logarithmic values of androsterone and age, the results again fitting a parabolic curve reaching a peak at about 40 years of age. As with aetiocholanolone, however, the age of 38 was used for the further analysis. Analysis of covariance showed again that a common coefficient could be used, and the drawn regression lines (Fig. 4) indicated that the group

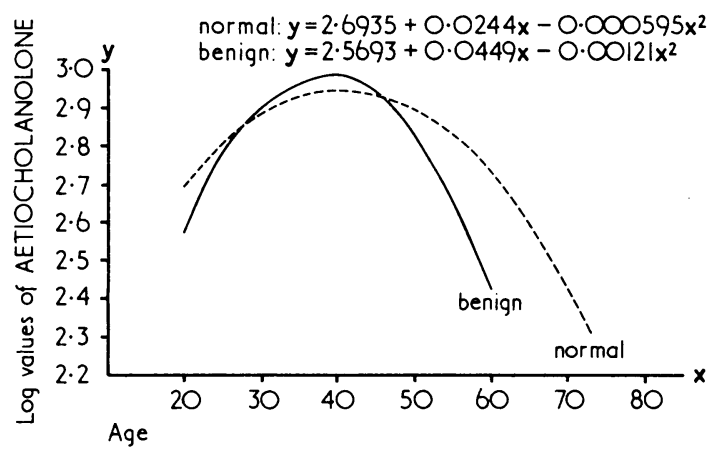

FIG. 1.-Relationship of urinary excretion of actiocholanolone $(\log \mu \mathrm{g} . / 24 \mathrm{hr}$.) to age in 21 normal women and 63 patients with henign disease of the breast.

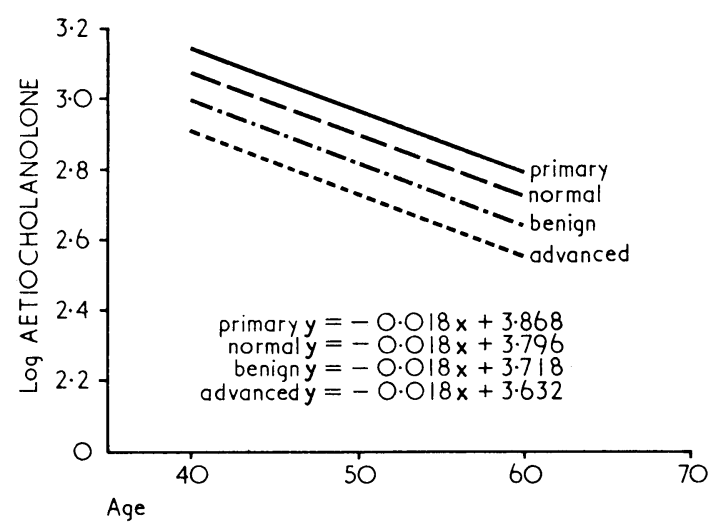

FIG. 2.-Relationship of urinary excretion of actiocholannlone $(\log \mu \mathrm{g} / 24 \mathrm{hr}$.) to age in 16 normal women, 39 women lone (log $\mu \mathrm{g}$. $24 \mathrm{hr}$.) to age in 16 normal women, 39 women with benign disease, and 90 women with malignant breast
discase over 38 years of age. Twenty-nine of these had primary and $6 \mathrm{l}$ advanced cancer.

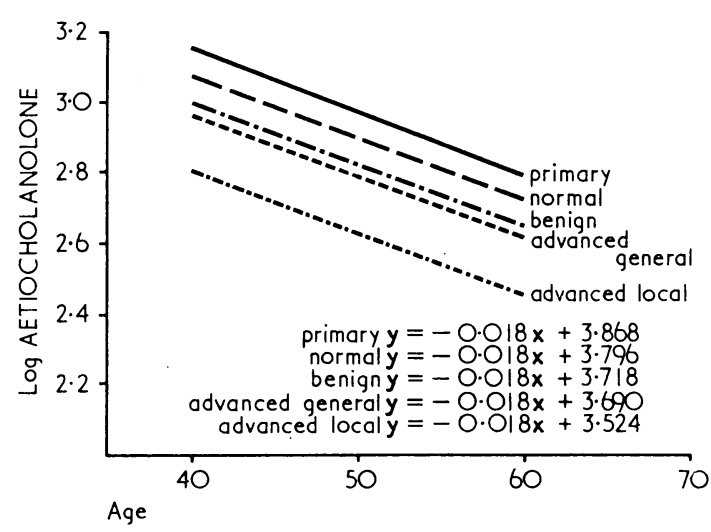

FIG. 3.-Relationship of urinary excretion of aetiocholanolone (log $\mu \mathrm{g} .124 \mathrm{hr}$.) to age, including subgroups of advanced cancer of the breast. These consisted of 21 patients with localized and 40 with gencralized disease. 


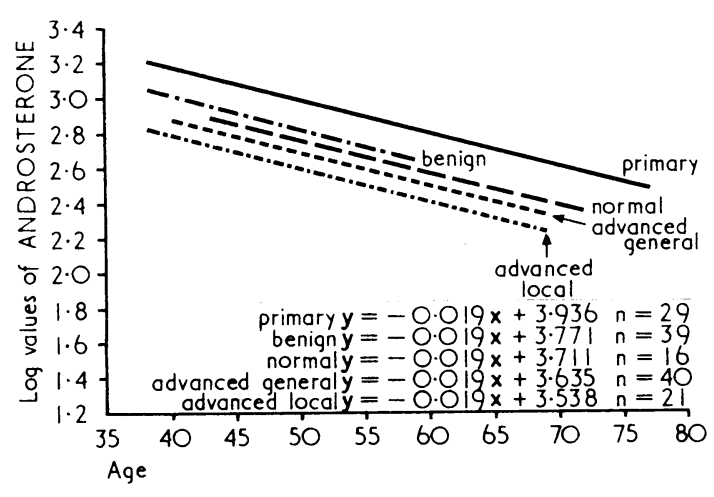

FIG. 4.-Relationship of urinary excretion of androsterone (log $\mu \mathrm{g} . / 24 \mathrm{hr}$.) to age in groups as in Fig. 3.

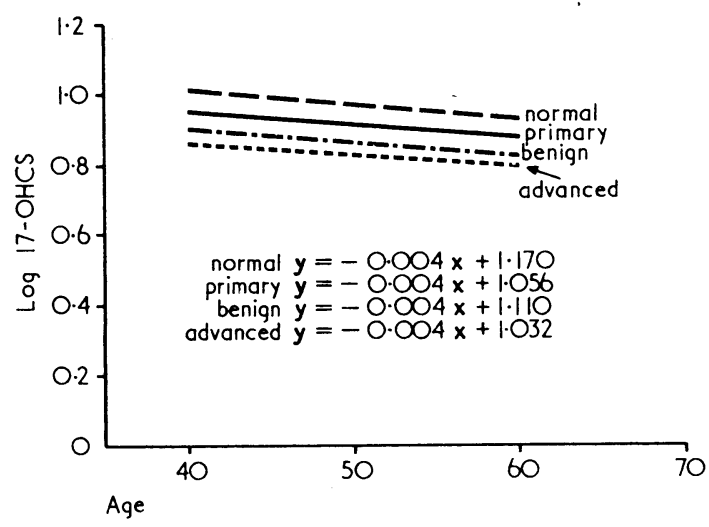

FIG. 5.-Relationship of urinary excretion of 17-hydroxycorticosteroids (log mg./24 hr.) to age in groups as in Fig. 3.

with advanced localized breast cancer again, regardless of age, had the lowest levels of androsterone. The difference was not as great as shown with aetiocholanolone.

\section{7-OHCS Analysis}

The mean values of $17-\mathrm{OHCS}$ excretion did not vary between the different groups (Table II). Furthermore, detailed analysis did not show the parabolic relationship between urinary excretion and age, and a regression analysis failed to reveal any differences (Fig. 5).

\section{Discussion}

The results we describe support the view of others (Bulbrook et al., 1960; Bulbrook, 1965; Juret, 1968; Wilson and Moore, 1968) that steroid excretion in many patients with breast cancer differs from that of the normal population. Equally clearly our conclusions regarding this difference throughout the spectrum of breast disease do not entirely coincide with some previous opinions. The figures show that in the population studied by the methodology used in our laboratory 11-DOKS excretion in normal women and in those with benign breast disease or primary breast cancer are virtually indistinguishable. Abnormal levels of 11-DOKS were found only in patients with advanced cancer of the breast and, so far as our data are concerned, no abnormality of steroid excretion was present in patients with primary cancer of the breast. This was in contrast to earlier observations of Hayward and Bulbrook (1968).

It was also noted that patients with advanced localized disease predominantly show abnormal steroid excretion, an interesting observation in the light of experience that such patients tend to respond badly to endocrine ablation. Furthermore, in a controlled randomized trial to determine whether early endocrine ablation ( ${ }^{90} \mathrm{Y}$ implant of the pituitary) carried any advantage over delaying it until other simpler forms of treatment have been tried, we found that patients with localized disease again behaved differently from those in whom widespread dissemination had occurred (Stewart et al., 1969).

Rationalization of these observations in physiological terms is somewhat difficult. Perhaps the discriminating power of the Bulbrook discriminant function is in some way related to the distribution of the disease. Noteworthy are the observations of Bulbrook (1969) that the original results from the application of the discriminant function to patients with primary breast cancer (Hayward and Bulbrook, 1968) required some modification when larger numbers were studied, though they could still state that assays of 11-DOKS and 17-OHCS are of value in identifying patients with primary breast cancer at high risk of recurrence (Bulbrook, 1969). Our results would therefore indicate that an abnormal level of urinary steroids is confined to patients with advanced cancer of the breast, and would appear to be a result of rather than a precedent to spread of the disease. Interestingly, however, recent work on the extent of metabolism by breast tissue of steroids found in the plasma (Jones, Cameron, Griffiths, Gleave, and Forrest, 1970; Griffiths, Jones, Cameron, Gleave, and Forrest, 1970) would not support the view that such metabolism contributes significantly to the pattern of 11-DOKS excretion. Obviously a great deal has still to be learnt about the endocrinology of breast cancer.

We wish to express our gratitude to the Tenovus Organization for generous financial support. We are also grateful to Dr. R. D. Bulbrook. and to Mr. B. S. Thomas, of the Imperial Cancer Research Fund. London, for their unstinted encouragement and practical assistance. Thanks are also due to Mrs. Ursula Jones and the staff of the department of surgery, Cardiff Royal Infirmarv. for their assistance in the collection of urine specimens. $\mathrm{Mr}$. D. Wilson, Miss R. Gardner, and Miss T. Gardner performed a maior part of the urinary analvses, and Miss $K$. Davis kindly helped with some of the statistical analyses. We would also thank Mr. R. Marshall and his staff of the department of medical illustration for their assistance in the preparation of the diagrams.

\section{REFERENCES}

Ahlquist, K. A., Jackson, A. W., and Stewart, J. G. (1968). British Medical fournal, 1, 217.

Atkins, H., et al. (1964). Lancet, 2, 1133.

Bulbrook, R. D. (1965). Vitamins and Hormones, 23, 329.

Bulbrook, R. D. (1969). In The Human Adrenal Gland and its Relation to Breast Cancer, ed. K. Griffiths and E. H. D. Cameron, p. 82. Caerphilly, Alpha Omega Alpha Publishing Co.

Bullbrook, R. D., Greenwood, F. C., and Hayward, J. L. (1960). Lancet, 1,

1154.
Burstein, S., and Lieberman, S. (1958). Journal of Biological Chemistry, 233, 331 .

Few, J. D. (1961). Fournal of Endocrinology, 22, 31.

Griffiths, K., Jones, D., Cameron, E. H. D., Gleave, E. N., and Forrest, A. P. M. (1970). Proceedings of a Breast Cancer Workshop: Estrogen Target Tissues and Neoplasia. Buffalo, June, 1970, ed. T. Dao. Chicago, University of Chicago Press. In press.

Hayward, J. L., and Bulbrook, R. D. (1968). In Prognostic Factors in Breast Cancer, ed. A. P. M. Forrest, and P. B. Kunkler, p. 383. Edinburgh, Livingstone.

Jones, D., Cameron, E. H. D., Griffiths, K., Gleave, E. N., and Forrest, A. P. M. (1970). Biochemical fournal, 116, 919 .

Juret, P. (1968). In Prognostic Factors in Breast Cancer, ed. A. P. M. Forrest, and P. B. Kunkler, n. 393. Edinburgh, Livingstone.

Miller, H., and Durant, J. A. (1968). Clinical Biochemistry, 1, 287.

Miller, H., Durant, J. A., Jacobs, A. C., and Allison, J. F. (1967). British Medical fournal, 1,147 .

Stewart, H. I., et al. (1969). Lancet, 2, 816

Talalav, P., Fishman, W. H., and Huggins, C. B. (1946). Fournal of Biological

Chemistry, 166, 757. In (a) Chromatography of Steroids in Biological
Thomas, B. S. (1965). In Fluids, ed. M. B. Lipsett, n. 1. New York, Plenum Press.

Thomas, B. S., and Bulbrook, R. D. (1964). Fournal of Chromatography, 14, 28.

Thomas, B. S., Bulbrook, R. D., Durant, J. A., Miller, H., and Russ, D. M. (1969). Clinical Biochemistry, 2, 311 .

Thomas, B. S., Bulbronk, R. D., and Hayward, J. L. (1967) British Medical fournal, 3, 523.

Wade, A. P., Davis, J. C., Tweedie, M. C. K., Clarke, C. A. ar.s Haggart, B. (1969). Lan , 1, 853 .

Wilson, R. E., and Mtoore. F. D. (1968). In Progroms Factors in Rreast Cancer, ed. A. P M. Ferrest, and P. B. Kunkler, p. $3 \%$ Eanbur?h. Livingstone. 